\title{
Membrane Lipid Composition and Heat Tolerance in Cool-season Turfgrasses, including a Hybrid Bluegrass
}

\author{
Kemin Su \\ Department of Horticulture and Landscape Architecture, Oklahoma State University, \\ Stillwater, OK 74078 \\ Dale J. Bremer ${ }^{1}$ \\ Department of Horticulture, Forestry and Recreation Resources, Kansas State University, \\ Manhattan, KS 66506 \\ Richard Jeannotte and Ruth Welti ${ }^{1}$ \\ Kansas Lipidomics Research Center, Division of Biology, Kansas State University, \\ Manhattan, KS 66506 \\ Celeste Yang \\ Department of Biostatistics, University of Alabama at Birmingham, Birmingham, AL 35294
}

\begin{abstract}
Additional Index words. ESI-MS/MS, kentucky bluegrass, lipid profiling, glycolipids, phospholipids, tall fescue
Abstract. Cool-season turfgrasses may experience heat stress during summer. Hybrid bluegrasses (HBGs), crosses between kentucky bluegrass [KBG (Poa pratensis L.)] and native texas bluegrass (Poa arachnifera Torr.), have improved heat tolerance but the mechanisms of heat tolerance are poorly understood. Our objectives were to quantitatively profile membrane lipid molecular species in three cool-season turfgrasses exposed to optimal $\left(22 / 15^{\circ} \mathrm{C}\right.$, $14 / 10 \mathrm{~h} \mathrm{light/dark)}$ and supra-optimal temperatures $\left(35 / 25^{\circ} \mathrm{C}\right.$ and $40 / 30{ }^{\circ} \mathrm{C}, 14 / 10 \mathrm{~h}$ light/dark). Grasses included a low heat-tolerant tall fescue [TF (Festuca arundinacea Schreb. 'Dynasty')], a mid-heat-tolerant KBG ('Apollo'), and a heat-tolerant HBG ('Thermal Blue'). At high temperature, glycolipid digalactosyldiacylglycerol (DGDG) in HBG was $12 \%$ and $16 \%$ greater than in KBG and TF, respectively, and the ratio DGDG to monogalactosyldiacylglycerol was $19 \%$ and $44 \%$ greater in $\mathrm{HBG}$ than in KBG and TF, respectively. Greater heat tolerance in HBG and KBG was associated with higher contents of phosphatidylethanolamine and phosphatidylglycerol, and with reduced overall unsaturation compared with TF. Overall, 20 lipid molecular species were present in greater amounts and another 20 species in lesser amounts in HBG and KBG than in TF. Results suggest 40 membrane lipid molecules are potential biomarkers for heat tolerance and that compositional changes in membrane lipids in response to heat contribute to differences in heat tolerance among cool-season grasses.
\end{abstract}

Heat stress is often a problem in cool-season turfgrasses during summer months in the transition zone of the United States. This region covers 480 to $1120 \mathrm{~km}$ north to south between the northern regions where cool-season grasses are adapted and the southern regions where warm-season grasses are adapted (Dunn and Diesburg, 2004). Predictions of higher temperatures from global warming suggest that heat stress in cool-season turfgrasses may become more common in some regions, including in and north of the present-day transition

Received for publication 5 Apr. 2009. Accepted for publication 17 Sept. 2009. This is contribution no. 09-389-J from the Kansas Agriculture Experiment Station.

We thank the Scotts Co. and Kansas Turfgrass Foundation for financial support, Dr. Channa Rajashekar for providing laboratory facilities, and Ms. Mary Roth from Kansas Lipidomics Research Center (KLRC) for technical help. The KLRC Analytical Laboratory and its development of lipid profiling methods was supported by grants from the National Science Foundation (MCB-0455318 and DBI-0521587) and the National Science Foundation's EPSCoR program (EPS-0236913), with matching support from the State of Kansas through Kansas Technology Enterprise Corporation and Kansas State University, as well from National Institutes of Health grant P20 RR016475 from the INBRE program of the National Center for Research Resources. In particular, we thank Kansas State's Targeted Excellence Program.

${ }^{1}$ Corresponding authors. E-mail: bremer@ksu.edu; welti@ksu.edu. zone (National Assessment Synthesis Team, 2000). Thus, understanding the mechanisms of heat tolerance is increasingly important for turfgrass breeders and managers.

Cellular membranes, which are selectively permeable lipid bilayers with associated and embedded proteins, have long been proposed as one of the prime sites of vulnerability or tolerance to heat and cold stress in plants (Armond et al., 1980; Quinn, 1988; Vigh et al., 1993). The composition of lipid molecular species in cellular membranes may change in response to environmental stress (Grover et al., 2000; Welti et al., 2002). The major categories of plant cellular membrane lipids are glycolipids and phospholipids (Lea and Leegood, 1993). Glycolipids are the most abundant lipids in plastids and thus, in photosynthetic tissues, and are believed to be highly vulnerable to damage by heat stress (Armond et al., 1980; Weis and Berry, 1988; Welti et al., 2002). The two most abundant glycolipids in leaves are monogalactosyldiacylglycerol (MGDG) and digalactosyldiacylglycerol (DGDG). Phospholipids are the structural building blocks of extraplastidic membranes, although one phospholipid, phosphatidylglycerol, is found mainly in the plastid. Membrane lipids modulate membrane trafficking of select chemicals, are precursors of intracellular signaling molecules, and participate in the regulation 
and control of cellular function and response to stresses or injury through signal transduction processes (Haucke and Di Paolo, 2007; Wang, 2004).

To identify the possible roles of membrane lipids in heat tolerance mechanisms in turfgrasses, we sought to identify and quantify lipid molecular species in response to heat stress in cultivars with varying heat tolerance. Until recently, it has been difficult to study membrane lipid species and their changes during environmental stresses because of the complexity of lipid molecular species and limited analytical procedures. Recently, however, a highly sensitive, selective, and efficient approach based on electrospray ionization tandem mass spectrometry (ESI-MS/MS) has been developed to comprehensively analyze lipid composition in plants (Brügger et al., 1997; Han and Gross, 2005; Welti et al., 2002, 2007; Welti and Wang, 2004). In this study, the ESI-MS/MS approach was used to profile membrane lipid changes in three cool-season grasses under optimal and supra-optimal growth temperatures. Turfgrasses selected for this study were the same as those in a related study (Su et al., 2007). In that study, we concluded that, of three cool-season turfgrasses, a hybrid bluegrasses (HBG; 'Thermal blue') that had greater visual quality, gross photosynthesis, and dry matter production was most heat tolerant, a tall fescue (TF) was least heat tolerant, and a kentucky bluegrass (KBG) was midway between the HBG and TF in heat tolerance; the HBG turfgrass is a genetic cross between native texas bluegrass and KBG (Read et al., 1999).

The objectives in the current study were to quantify membrane lipid molecular species under optimal and supraoptimal temperatures, to identify relationships between specific lipid compositions and heat tolerance, and to identify specific membrane lipid molecules as potential biomarkers for heat tolerance in turfgrass.

\section{Materials and Methods}

Plant preparation, maintenance, and treatments. Sod plugs of three grasses (HBG, KBG, and TF) were collected on 9 Sept. 2005 from established swards at the Rocky Ford Turfgrass Research Center near Manhattan, KS (lat. 39¹3'53"N, long. $\left.96^{\circ} 34^{\prime} 51^{\prime \prime} \mathrm{W}\right)$ and planted in 15 lysimeters $(10 \mathrm{~cm}$ diameter by $40 \mathrm{~cm}$ deep). Lysimeters were filled with a mixture of sand and topsoil $(1: 1, \mathrm{v}: \mathrm{v})$ and were maintained in a greenhouse for 2 weeks. Average day/night air temperature was $24 / 15^{\circ} \mathrm{C}$ and supplemental light with incandescent lamps was included for $14 \mathrm{~h} \cdot \mathrm{d}^{-1}$. Grasses were clipped weekly at $6.5 \mathrm{~cm}$. During the first week, irrigation was applied with a mist system that was automatically turned on four times per day for $5 \mathrm{~min}$ each to keep soil wet. During the second week, turfgrasses were watered twice with fertilizer water at $0.25 \mathrm{~g} \cdot \mathrm{L}^{-1} \mathrm{~N}$ of Peters Peat-lite Special 20N-4.4P-16.6K water-soluble fertilizer (Scotts-Sierra Horticultural Products, Marysville, $\mathrm{OH}$ ).

After 2 weeks in the greenhouse, on 23 Sept. 2005, lysimeters were transferred to a growth chamber and maintained for $105 \mathrm{~d}$ at optimal growth temperature $\left(22 / 15^{\circ} \mathrm{C}, 14 / 10 \mathrm{~h}\right.$ light/dark) with photosynthetically active radiation $(P A R)$ at $580 \mu \mathrm{mol} \cdot \mathrm{m}^{-2} \cdot \mathrm{s}^{-1}$ during the daylight period. Turfgrasses were mowed once per week at $6.5 \mathrm{~cm}$ and were irrigated every $3 \mathrm{~d}$. To maintain well-watered conditions, $100 \%$ of water lost via evapotranspiration (ET) during the previous $3 \mathrm{~d}$ was replaced; $100 \%$ ET was determined gravimetrically with the lysimeters
(Bremer, 2003). Using this method, lysimeters were irrigated, allowed to drain until free drainage ceased, sealed, and weighed. Lysimeters were weighed again after $3 \mathrm{~d}$ and the water loss was attributed to ET. Turfgrasses were fertilized every $6 \mathrm{~d}$ with a solution supplying $20 \mathrm{~kg} \cdot \mathrm{ha}^{-1} \mathrm{~N}(15 \mathrm{~N}-13.1 \mathrm{P}-$ $12.5 \mathrm{~K})$.

On 10 Jan. 2006, the growth chamber temperature was increased to $35 / 25{ }^{\circ} \mathrm{C}(14 / 10 \mathrm{~h}$ light/dark). However, by 15 Feb., visual quality ratings indicated negligible differences in heat tolerance among species and thus, temperatures were increased to $40 / 30{ }^{\circ} \mathrm{C}(14 / 10 \mathrm{~h}$ light/dark) from $15 \mathrm{Feb}$. through 13 Mar. Thus, turfgrasses were maintained for a total of $63 \mathrm{~d}$ under supra-optimal growth temperatures, which included $36 \mathrm{~d}$ at $35 / 25{ }^{\circ} \mathrm{C}(14 / 10 \mathrm{~h} \mathrm{light/dark})$ and $27 \mathrm{~d}$ at $40 / 30{ }^{\circ} \mathrm{C}$ (14/10 h light/dark).

LIPID EXTRACTION. Lipids were extracted according to the procedure of Devaiah et al. (2006) with minor modifications. Briefly, five leaves at about the same age were collected from each lysimeter on 9 Jan. 2006 (i.e., the end of $105 \mathrm{~d}$ period under optimal growth temperature) and 13 Mar. 2006 (i.e., the end of $63 \mathrm{~d}$ under supra-optimal growth temperature). Leaves were quickly immersed in $3 \mathrm{~mL}$ of isopropanol with $0.01 \%$ butylated hydroxytoluene at $75{ }^{\circ} \mathrm{C}$ to inactivate lipolytic activity. After $15 \mathrm{~min}, 1.5 \mathrm{~mL}$ of chloroform and $0.6 \mathrm{~mL}$ of water were added and the tubes were shaken for $1 \mathrm{~h}$. Thereafter, the extract was removed and replaced with chloroform/methanol (2:1) with $0.01 \%$ butylated hydroxytoluene and the tubes were shaken for $30 \mathrm{~min}$. The latter procedure was repeated five times until the leaves of every sample appeared white. The remaining leaf material was then dried overnight at $105^{\circ} \mathrm{C}$ and weighed. The combined extracts were washed once with $1 \mathrm{~mL}$ of $1 \mathrm{M} \mathrm{KCl}$ and once with $2 \mathrm{~mL}$ of water, evaporated under nitrogen, and dissolved in $1 \mathrm{~mL}$ of chloroform.

ESI-MS/MS LIPID PROFILING. An automated ESI-MS/MS approach was used, and data acquisition and analysis and acyl group identification were carried out as described previously

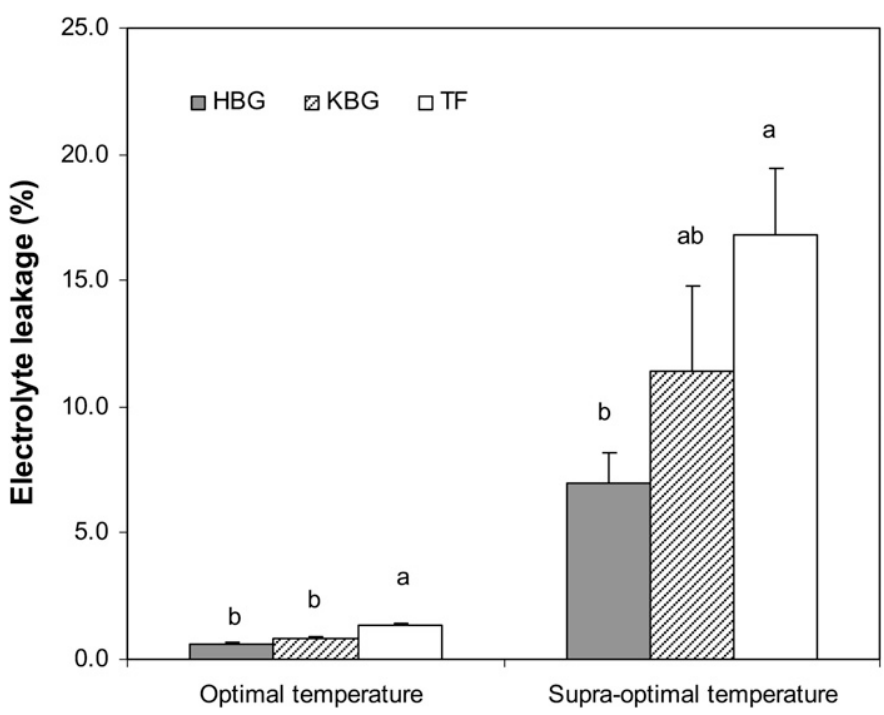

Fig. 1. Electrolyte leakage of 'Thermal Blue' hybrid bluegrass (HBG), 'Apollo' kentucky bluegrass (KBG), and 'Dynasty' tall fescue (TF) under optimal (22/ $15^{\circ} \mathrm{C}, 14 / 10 \mathrm{~h}$ light/dark) and supra-optimal $\left(35 / 25^{\circ} \mathrm{C}\right.$ and $40 / 30{ }^{\circ} \mathrm{C}, 14 / 10 \mathrm{~h}$ light/dark) temperatures. Error bars indicate $\pm \mathrm{SE}(\mathrm{n}=5)$. Means with the same letters under the same temperature treatment (i.e., optimal or supra-optimal) were not significantly different $(P=0.05)$. 
(Devaiah et al., 2006) with modifications. The samples were dissolved in $1 \mathrm{~mL}$ of chloroform. An aliquot of 7 to $50 \mu \mathrm{L}$ of extract in chloroform was used. Precise amounts of internal standards, obtained and quantified as previously described (Welti et al., 2002), were added in the following quantities (with some small variation in amounts in different batches of internal standards): $0.66 \mathrm{~nm}$ di14:0-phosphatidylcholine (PC), 0.66 nм di24:1-PC, 0.66 nм 13:0-1ysoPC, 0.66 nм 19:0-lysoPC, $0.36 \mathrm{~nm}$ di14:0-phosphatidylethanolamine (PE), $0.36 \mathrm{~nm}$ di24:1-PE, 0.36 пм 14:0-lysoPE, 0.36 пм 18:0-lysoPE, $0.36 \mathrm{~nm}$ di14:0- phosphatidylglycerol (PG), $0.36 \mathrm{~nm}$ di24:1PG, 0.36 nм 14:0-lysoPG, 0.36 nм 18:0-lysoPG, 0.36 nм di14:0-phosphatidic acid (PA), 0.36 nм di20:0(phytanoyl)-
PA, 0.24 nм di14:0-phosphatidylserine (PS), 0.24 nм di20:0(phytanoyl)-PS, 0.20 nM 16:0 to 18:0-phosphatidylinositol (PI), $0.16 \mathrm{~nm}$ di18:0-PI, $2.01 \mathrm{~nm} 16: 0$ to $18: 0-\mathrm{MGDG}$, 0.39 nм di18:0-MGDG, 0.49 nм 16:0 to 18:0-DGDG, and 0.71 nM di18:0-DGDG. The sample and internal standard mixture were combined with solvents such that the ratio of chloroform/ methanol/300 mu ammonium acetate in water was 300/665/35, and the final volume was $1.2 \mathrm{~mL}$.

Unfractionated lipid extracts were introduced by continuous infusion into the ESI source on a triple quadrupole MS/MS (API 4000; Applied Biosystems, Foster City, CA). Samples were introduced using an autosampler (LC Mini PAL; CTC Analytics, Zwingen, Switzerland) fitted with the required

Table 1. Membrane lipid composition (mol\%) and digalactosyldiacylglycerol (DGDG):monogalactosyldiacylglycerol (MGDG) (ratio) of 'Thermal Blue' hybrid bluegrass (HBG), 'Apollo' kentucky bluegrass (KBG), and 'Dynasty' tall fescue (TF) under optimal $\left(22 / 15^{\circ} \mathrm{C}\right.$, $14 \mathrm{~h}$ light $/ 10 \mathrm{~h}$ dark) and supra-optimal $\left(35 / 25^{\circ} \mathrm{C}\right.$ and $40 / 30^{\circ} \mathrm{C}, 14 \mathrm{~h}$ light/10 h dark) temperatures.

\begin{tabular}{|c|c|c|c|c|c|c|}
\hline \multirow[b]{2}{*}{ Lipid species ${ }^{z}$} & \multicolumn{3}{|c|}{ Optimal temperature } & \multicolumn{3}{|c|}{ Supra-optimal temperature } \\
\hline & $\mathrm{HBG}$ & KBG & $\mathrm{TF}$ & $\mathrm{HBG}$ & KBG & $\mathrm{TF}$ \\
\hline MGDG (mol\%) & $50.12 \mathrm{a}^{\mathrm{y}}$ & $50.31 \mathrm{a}$ & $48.41 b$ & $35.95 \mathrm{~b}$ & $38.42 \mathrm{~b}$ & $44.97 \mathrm{a}$ \\
\hline Subtotal of glycolipids (mol\%) & $79.51 \mathrm{a}$ & $79.90 \mathrm{a}$ & $79.40 \mathrm{a}$ & $75.92 \mathrm{~b}$ & $74.03 \mathrm{~b}$ & $79.54 \mathrm{a}$ \\
\hline DGDG:MGDG (ratio) & $0.59 \mathrm{~b}$ & $0.59 \mathrm{~b}$ & $0.64 \mathrm{a}$ & $1.11 \mathrm{a}$ & $0.93 \mathrm{~b}$ & $0.77 \mathrm{c}$ \\
\hline $\mathrm{PE}(\mathrm{mol} \%)$ & $4.50 \mathrm{a}$ & $4.58 \mathrm{a}$ & $4.39 \mathrm{a}$ & $7.10 \mathrm{a}$ & $7.49 \mathrm{a}$ & $4.87 \mathrm{~b}$ \\
\hline PG $(\mathrm{mol} \%)$ & $5.14 \mathrm{a}$ & $5.14 \mathrm{a}$ & $4.26 \mathrm{~b}$ & $4.31 \mathrm{a}$ & $3.93 \mathrm{a}$ & $2.70 \mathrm{~b}$ \\
\hline PI $(\mathrm{mol} \%)$ & $1.13 \mathrm{~b}$ & $1.15 \mathrm{~b}$ & $1.35 \mathrm{a}$ & $1.80 \mathrm{a}$ & $1.81 \mathrm{a}$ & $1.76 \mathrm{a}$ \\
\hline PS (mol\%) & $0.24 \mathrm{ab}$ & $0.20 \mathrm{~b}$ & $0.29 \mathrm{a}$ & $0.61 \mathrm{a}$ & $0.67 \mathrm{a}$ & $0.48 \mathrm{a}$ \\
\hline $\mathrm{PA}(\mathrm{mol} \%)$ & $0.11 \mathrm{a}$ & $0.12 \mathrm{a}$ & $0.14 \mathrm{a}$ & $0.20 \mathrm{a}$ & $0.27 \mathrm{a}$ & $0.23 \mathrm{a}$ \\
\hline
\end{tabular}

${ }^{\mathrm{z}} \mathrm{PC}=$ phosphatidylcholine, $\mathrm{PE}=$ phosphatidylethanolamine, $\mathrm{PG}=$ phosphatidylglycerol, $\mathrm{PI}=$ phosphatidylinositol, $\mathrm{PS}=$ phosphatidylserine, $\mathrm{PA}=$ phosphatidic acid.

${ }^{\mathrm{y}}$ Means followed by the same letter within a row and temperature subgroup (i.e., optimal or supra-optimal) were not significantly different (adjusting $P=0.05$ by the false discovery rate method).

Table 2. Double-bond index of lipid species of 'Thermal Blue' hybrid bluegrass (HBG), 'Apollo' kentucky bluegrass (KBG), and 'Dynasty' tall fescue (TF) under optimal $\left(22 / 15^{\circ} \mathrm{C}, 14 \mathrm{~h}\right.$ light/10 h dark) and supra-optimal $\left(35 / 25^{\circ} \mathrm{C}\right.$ and $40 / 30{ }^{\circ} \mathrm{C}, 14 \mathrm{~h}$ light/10 h dark) temperatures.

\begin{tabular}{|c|c|c|c|c|c|c|}
\hline \multirow[b]{3}{*}{ Lipid species ${ }^{z}$} & \multicolumn{6}{|c|}{ Double-bond index } \\
\hline & \multicolumn{3}{|c|}{ Optimal temperature } & \multicolumn{3}{|c|}{ Supra-optimal temperature } \\
\hline & $\begin{array}{l}\mathrm{HBG} \\
\end{array}$ & KBG & TF & HBG & KBG & $\mathrm{TF}$ \\
\hline \multicolumn{7}{|c|}{ Glycolipids } \\
\hline DGDG & $4.97 \mathrm{a}$ & $4.86 \mathrm{a}$ & $4.98 \mathrm{a}$ & $3.61 \mathrm{c}$ & $3.82 \mathrm{~b}$ & $4.11 \mathrm{a}$ \\
\hline \multicolumn{7}{|c|}{ Phospholipids } \\
\hline PE & $3.32 \mathrm{~b}$ & $3.27 \mathrm{~b}$ & $3.57 \mathrm{a}$ & $2.94 \mathrm{~b}$ & $3.05 \mathrm{a}$ & $3.10 \mathrm{a}$ \\
\hline PG & $3.20 \mathrm{a}$ & $3.23 \mathrm{a}$ & $3.08 \mathrm{~b}$ & $1.96 \mathrm{a}$ & $1.83 \mathrm{ab}$ & $1.70 \mathrm{~b}$ \\
\hline PI & $2.40 \mathrm{~b}$ & $2.37 \mathrm{~b}$ & $2.59 \mathrm{a}$ & $1.74 \mathrm{c}$ & $1.91 \mathrm{~b}$ & $2.15 \mathrm{a}$ \\
\hline PS & $2.40 \mathrm{~b}$ & $2.42 \mathrm{~b}$ & $2.74 \mathrm{a}$ & $2.15 \mathrm{~b}$ & $2.20 \mathrm{~b}$ & $2.28 \mathrm{a}$ \\
\hline PA & $3.36 \mathrm{a}$ & $3.45 \mathrm{a}$ & $3.18 \mathrm{a}$ & $3.09 \mathrm{a}$ & $3.15 \mathrm{a}$ & $3.21 \mathrm{a}$ \\
\hline Sum of lysoPC, lysoPE, and lysoPG & $1.46 \mathrm{a}$ & $1.30 \mathrm{a}$ & $2.02 \mathrm{a}$ & $0.99 \mathrm{a}$ & $0.83 \mathrm{a}$ & $0.85 \mathrm{a}$ \\
\hline
\end{tabular}

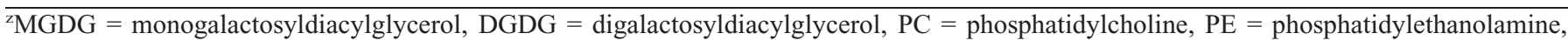
PG = phosphatidylglycerol, PI = phosphatidylinositol, PS = phosphatidylserine, PA = phosphatidic acid.

${ }^{\mathrm{y}}$ Means followed by the same letter within a row and temperature subgroup (i.e., optimal or supra-optimal) were not significantly different (adjusting $P=0.05$ by the false discovery rate method). 
injection loop for the acquisition time and were presented to the ESI needle at $30 \mu \mathrm{L} \cdot \mathrm{min}^{-1}$.

Sequential precursor and neutral loss scans of the extracts produce a series of spectra, with each spectrum revealing a set of lipid species containing a common head group fragment. Lipid species were detected with the following scans: PC and lysoPC, $[\mathrm{M}+\mathrm{H}]^{+}$ions in positive ion mode with precursor of 184.1 (Pre 184.1); PE and lysoPE, $[\mathrm{M}+\mathrm{H}]^{+}$ions in positive ion mode with neutral loss of 141.0 (NL 141.0); PG, lysoPG, and PA $[\mathrm{M}-\mathrm{H}]^{-}$in negative mode with Pre 152.9; PI, [M $\left.-\mathrm{H}\right]^{-}$ in negative ion mode with precursor 241.0; PS, [M $-\mathrm{H}]^{-}$ in negative ion mode with NL 87.0; $\mathrm{MGDG},\left[\mathrm{M}+\mathrm{NH}_{4}\right]^{+}$in positive ion mode with NL179.1; and DGDG, $\left[\mathrm{M}+\mathrm{NH}_{4}\right]^{+}$in positive ion mode with NL 341.1. The scan speed was 50 or 100 $\mu \mathrm{m} \cdot \mathrm{s}^{-1}$. The collision gas pressure was set at 2 (arbitrary units). The collision energies, with nitrogen in the collision cell, were $+28 \mathrm{~V}$ for $\mathrm{PE},+40 \mathrm{~V}$ for $\mathrm{PC},-57 \mathrm{~V}$ for $\mathrm{PG}$ and $\mathrm{PA},-34 \mathrm{~V}$ for PS, $-58 \mathrm{~V}$ for PI, $+21 \mathrm{~V}$ for MGDG, and $+24 \mathrm{~V}$ for DGDG. Declustering potentials were +100 $\mathrm{V}$ for $\mathrm{PE}$ and $\mathrm{PC},-100 \mathrm{~V}$ for $\mathrm{PA}$, PG, PI, and PS, and $+90 \mathrm{~V}$ for MGDG and DGDG. Entrance potentials were $+15 \mathrm{~V}$ for $\mathrm{PE},+14 \mathrm{~V}$ for PC, $-10 \mathrm{~V}$ for PI, PA, PG, and $\mathrm{PS}$, and $+10 \mathrm{~V}$ for $\mathrm{MGDG}$ and DGDG. Exit potentials were $+11 \mathrm{~V}$ for $\mathrm{PE},+14 \mathrm{~V}$ for $\mathrm{PC},-15 \mathrm{~V}$ for PI, $-14 \mathrm{~V}$ for $\mathrm{PA}$ and $\mathrm{PG},-13 \mathrm{~V}$ for PS, and $+23 \mathrm{~V}$ for MGDG and DGDG. The mass analyzers were adjusted to a resolution of $0.7 \mu \mathrm{m}$ full width at half height. For each spectrum, 9 to 150 continuum scans were averaged in multiple channel analyzer (MCA) mode. The source temperature (heated nebulizer) was $100{ }^{\circ} \mathrm{C}$, the interface heater was on, $+5.5 \mathrm{kV}$ or $-4.5 \mathrm{kV}$ were applied to the electrospray capillary, the curtain gas was set at 20 (arbitrary units), and the two ion source gases were set at 45 (arbitrary units).

The background of each spectrum was subtracted, the data were smoothed, and peak areas were integrated using a custom script and Applied Biosystems Analyst software. The lipids in each class were quantified in comparison with the two internal standards of that class. The first and typically every 11 th set of mass spectra were acquired on the internal standard mixture only. Peaks corresponding to the target lipids in these spectra were identified and molar amounts were calculated in comparison with the internal standards on the same lipid class. To correct for chemical or instrumental noise in the samples, the molar amount of each lipid metabolite detected in the "internal content $<0.1 \%$. standards only" spectra was subtracted from the molar amount of each metabolite calculated in each set of sample spectra. The data from each "internal standards only" set of spectra were used to correct the data from the following 10 samples. Finally, the data were corrected for the fraction of the sample analyzed and normalized to the sample "dry weights" to produce data in the units nanomoles per milligram. All the lipid data presented in the results and discussion section were the percentage of individual species to the total lipid content (mol\%).

Double-bond indices (DBI), which indicate the saturation level of lipids (i.e., greater DBI mean less saturation of lipid species or more unsaturation), were calculated by the equation: $\mathrm{DBI}=[\operatorname{sum}$ of $(\mathrm{N} \times \mathrm{mol} \%$ lipid molecular species $)] / 100$, where $\mathrm{N}$ is the number of double bonds in each lipid molecular species and $\mathrm{mol} \%$ refers to $\mathrm{mol} \%$ of a complex lipid class (Chen et al., 2006).

Electrolyte Leakage. The thermostability of turfgrass cell membranes was estimated by measuring leaf electrolyte leakage.
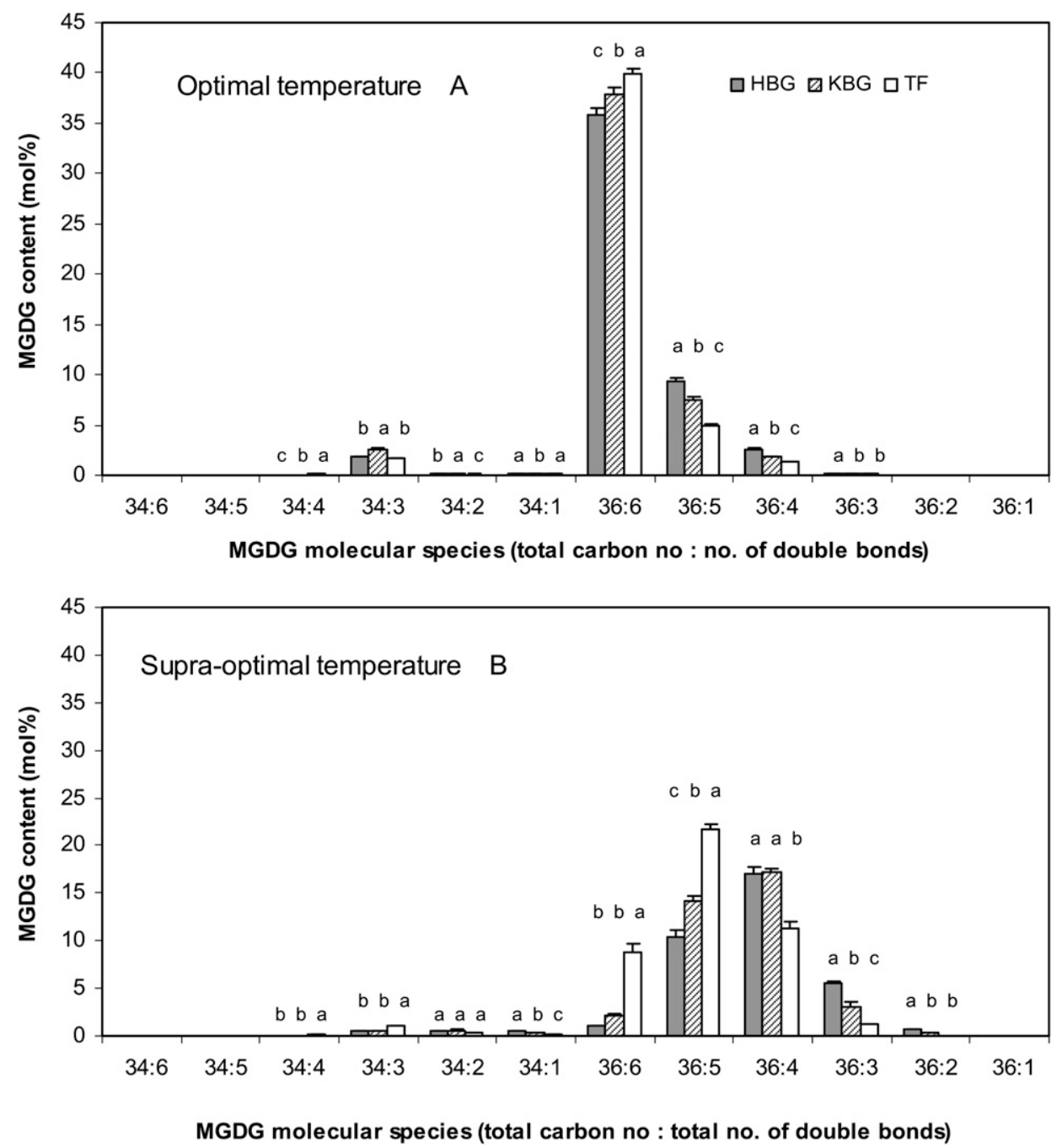

Fig. 2. The monogalactosyldiacylglycerol (MGDG) molecular species composition (mol\%) of 'Thermal Blue' hybrid bluegrass (HBG), 'Apollo' kentucky bluegrass (KBG), and 'Dynasty' tall fescue (TF) under (A) optimal $\left(22 / 15^{\circ} \mathrm{C}, 14 / 10 \mathrm{~h} \mathrm{light} /\right.$ dark $)$ and $\left(\right.$ B) supra-optimal $\left(35 / 25^{\circ} \mathrm{C}\right.$ and $40 / 30{ }^{\circ} \mathrm{C}, 14 / 10 \mathrm{~h}$ light/dark) temperatures. Means with the same letters in each MGDG molecular species were not significantly different (adjusting $P=$ 0.05 by the false discovery rate method). Error bars indicate \pm SE $(n=4$ or 5$)$. Means without letters indicated 
Five living leaves about the same age were collected from each lysimeter on 9 Jan. 2006 (i.e., the end of 105 d under optimal temperature) and 13 Mar. 2006 (i.e., the end of $63 \mathrm{~d}$ under supraoptimal temperature). Each leaf was cut into two to three $2-\mathrm{cm}$ segments and rinsed three times with distilled deionized water. All rinsed leaf segments from each lysimeter were placed in a test tube containing $20 \mathrm{~mL}$ of deionized water. The test tubes were shaken on a shaker table at 120 RPM (Laboratory-Line Instruments, Melrose Park, IL) for $24 \mathrm{~h}$ to diffuse electrolytes that had leaked from cells (e.g., due to membranes damaged by heat stress treatment). After measuring conductivity $\left(\mathrm{C}_{1}\right)$ with a conductivity meter (model 32; Yellow Springs Instruments, Yellow Springs, $\mathrm{OH}$ ), the test tubes with leaf samples were placed in an autoclave at $140{ }^{\circ} \mathrm{C}$ for $20 \mathrm{~min}$ to destroy all cell membranes, shaken for $24 \mathrm{~h}$ to extract all electrolytes from the cells, and the conductivity $\left(\mathrm{C}_{2}\right)$ was measured again. The percentage of the total electrolytes that had leaked from cells during treatments was calculated as $\left(\mathrm{C}_{1} / \mathrm{C}_{2}\right) \times 100$. Lower electrolyte leakage indicates greater resistance to heat stress (i.e., greater cell membrane thermostability).

EXPERIMENTAL DESIGN AND STATISTICAL ANALYSIS. A completely randomized experimental design with five replications was used. The Q-test (Shoemaker et al., 1974) for identification and rejection of outliers was done on the replicates of all individual lipid species in each head group class. Multiple comparisons were performed among lipid molecular species using Proc MULTTEST of the Statistical Analysis System, version 9.1 (SAS Institute, Cary, NC). Means among the grasses under the same temperature treatment were separated using adjusted probability values and the false discovery rate (FDR) method at the 0.05 level of probability to control the number of false positives obtained when performing multiple hypothesis tests. For electrolyte leakage data, the GLM procedure of SAS (version 9.1; SAS Institute, Cary, NC) was used, and differences between means were separated by the SAS PDIFF option $(P=0.05)$. Principal component analysis (PCA) was used to compare multivariate data from membrane lipid profiles under supraoptimal growth temperature, thus reducing the numbers of variables to consider. PCA was performed using SYSTAT software (version 10; Systat Software, Richmond, CA).

\section{Results and Discussion}

After exposure to supra-optimal temperature, electrolyte leakage was lower in HBG than in TF (Fig. 1), indicating less damage to cellular membranes in HBG and, thus, a $<0.1 \%$. greater tolerance to heat in HBG than in TF (Marcum, 1998). These data are similar to those in our previous study (Su et al., 2007) in which we investigated the same turfgrass genotypes. In that study, the overall heat tolerance of KBG was midway between HBG and TF. Electrolyte leakage was also lower in HBG and KBG than in TF at optimal temperature (Fig. 1), but absolute differences in electrolyte leakage among the three grasses were markedly smaller (i.e., electrolyte leakage ranged from $0.6 \%$ to $1.4 \%$ ) than after the grasses were exposed to heat (i.e., $7.0 \%$ to $16.8 \%$ ). Furthermore, in our previous work, we observed no differences in electrolyte leakage among these three grasses at the optimal growth temperature ( $\mathrm{Su}$ et al., 2007).

GLyCoLIPIDS. When exposed to supra-optimal temperature, the amount of MGDG lipids decreased by $28 \%$ in $\mathrm{HBG}, 24 \%$ in $\mathrm{KBG}$, and $7 \%$ in TF. Under supra-optimal temperature, MGDG in $\mathrm{HBG}$ was $6 \%$ and $20 \%$ lower, respectively, than in KBG and TF (Table 1). Researches by others have indicated that a higher content of MGDG can threaten bilayer integrity by inducing a transition from a bilayer to a nonbilayer lipid phase (Quinn,
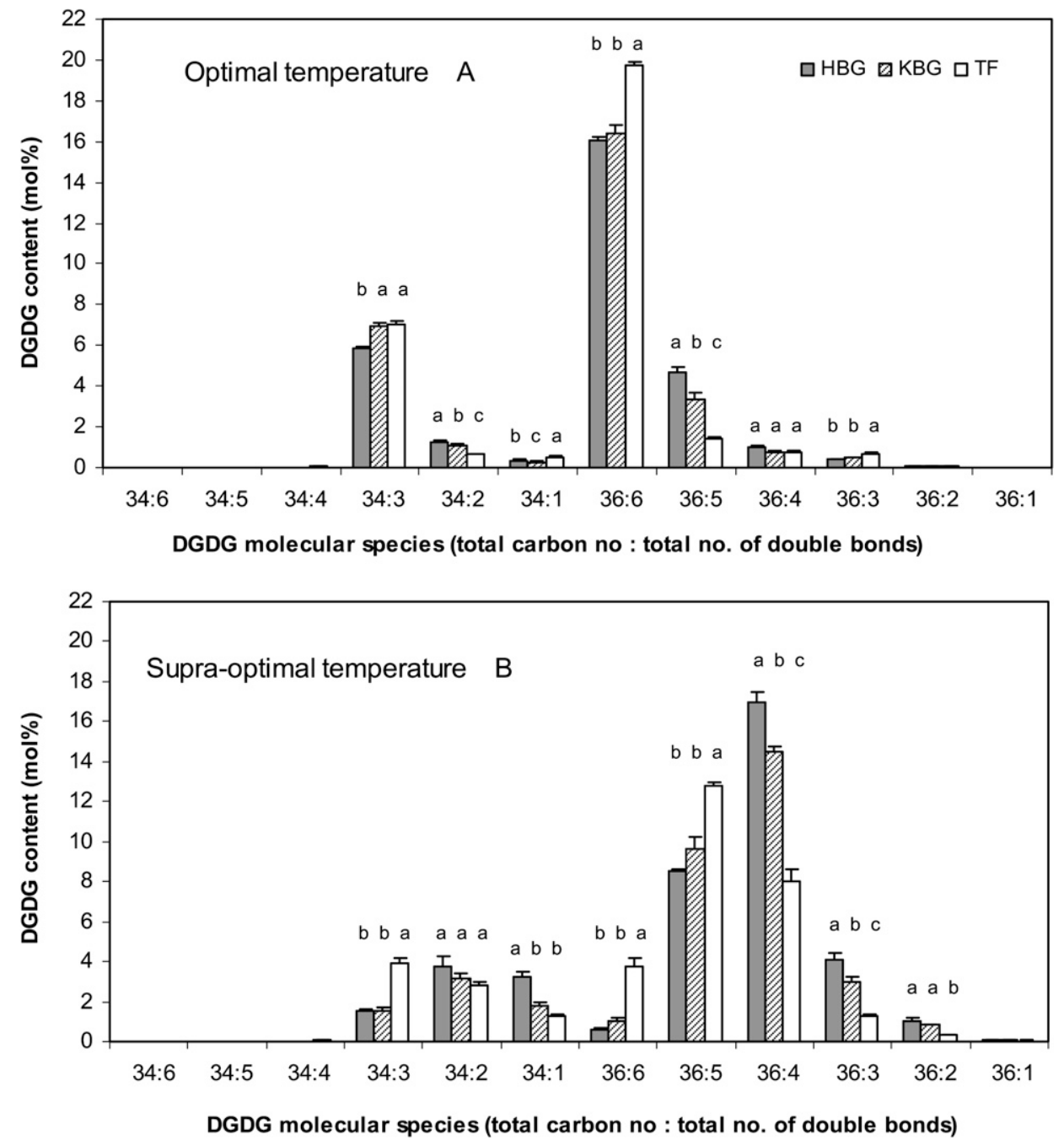

Fig. 3. The digalactosyldiacylglycerol (DGDG) molecular species composition (mol\%) of 'Thermal Blue' hybrid bluegrass (HBG), 'Apollo' kentucky bluegrass (KBG), and 'Dynasty' tall fescue (TF) under (A) optimal (22/ $15^{\circ} \mathrm{C}, 14 / 10 \mathrm{~h}$ light/dark) and (B) supra-optimal $\left(35 / 25^{\circ} \mathrm{C}\right.$ and $40 / 30{ }^{\circ} \mathrm{C}, 14 / 10 \mathrm{~h} \mathrm{light} /$ dark) temperatures. Means with the same letters in each DGDG molecular species were not significantly different (adjusting $P=0.05$ by the false discovery rate method). Error bars indicate $\pm \operatorname{SE}(n=4$ or 5$)$. Means without letters indicated content 
1988; Seddon, 1990; Webb and Green, 1991). Therefore, a greater reduction in MGDG in HBG than in TF after exposure to supra-optimal temperature may partially explain the greater heat tolerance of $\mathrm{HBG}$ relative to $\mathrm{TF}$.

When exposed to growth temperature, the amount of DGDG increased in all three turfgrasses; DGDG increased by $36 \%$ in $\mathrm{HBG}$, by $20 \%$ in $\mathrm{KBG}$, and by $12 \%$ in TF (Table 1 ). Our results with DGDG were consistent with published results that reported increases in DGDG with temperature (Chen et al., 2006; Di Baccio et al., 2002; Suss and Yordanov, 1986). In our study, DGDG in HBG was $12 \%$ and $16 \%$ greater than in $\mathrm{KBG}$ and TF, respectively, under supra-optimal temperature.

As a result of reduced MGDG and increased DGDG among the three grasses when exposed to supra-optimal growth temperature, the ratios of DGDG to MGDG increased to 1.12 in $\mathrm{HBG}$, to 0.93 in $\mathrm{KBG}$, and to 0.77 in TF (Table 1), which represents increases of $90 \%$ in $\mathrm{HBG}, 58 \%$ in $\mathrm{KBG}$, and $20 \%$ in TF. Our results were consistent with findings by others reporting that ratios of DGDG to MGDG increased with temperature (Chen et al., 2006; Di Baccio et al., 2002; Wang and Lin, 2006). The largest increase in DGDG to MGDG ratio in our study was associated with the greatest heat tolerance.

The exact role of glycolipids in plant thermotolerance is unclear. Much of the evidence linking membrane lipid composition with altered function is based on correlations, thus, it is difficult to obtain conclusive proof of cause and effect (Chen et al., 2006). However, the increased ratios of DGDG to MGDG with temperature may help maintain chloroplast membrane integrity and normal membrane protein function at high temperature. DGDG has a large polar head group that forms a more robust bilayer in an aqueous environment, whereas MGDG has a smaller head group that promotes the formation of a hexagonal phase (Hex II) structure that may result in the loss of bilayer integrity (Quinn, 1988; Seddon, 1990; Webb and Green, 1991). Consequently, greater DGDG to MGDG ratios in $\mathrm{HBG}$ than in $\mathrm{KBG}$ and $\mathrm{TF}$, as found in this study, may partially explain the higher heat tolerance reported in $\mathrm{HBG}$ among these three turfgrasses (Su et al., 2007; Fig. 1).

All three turfgrasses had similar DBI for glycolipids (DBI of MGDG and DGDG) under optimal growth temperature with the exception of TF, which had a slightly higher DBI of MGDG than HBG or KBG (Table 2). When exposed to supra-optimal temperature, however, the DBI of MGDG and DGDG were reduced in all three turfgrasses. The declines in $<0.1 \%$.
DBI of MGDG and DGDG among grasses after exposure to high temperature were largely caused by decreased 36:6MGDG (di18:3) (Fig. 2) and 36:6-DGDG (di 18:3) (Fig. 3) (Welti et al., 2002). Under supra-optimal temperature, the DBI of MGDG and DGDG was lowest in HBG and highest in TF (Table 2). These differences in DBI of MGDG and DGDG among grasses were strongly impacted by increased content of the less saturated species 36:4-MGDG and 36:4-DGDG after exposure to high temperature compared with 36:4 species before heat treatment (Figs. 2 and 3). Lower DBI indicates greater saturation of a lipid species (Chen et al., 2006; Stupnikova et al., 2006). Therefore, these data suggest that greater saturation levels in glycolipids contribute to greater heat tolerance. This is consistent with the established role of fatty acid saturation as related to heat tolerance (Kleinschmidt and McMahon, 1970; Pearcy, 1978; Quinn 1988).

Pноspholipids. The major classes of phospholipids detected by ESI-MS/MS in grass leaves included PC, PE, PG, and PI, and minor lipids included PS, PA, lysoPC, lysoPE, and lysoPG
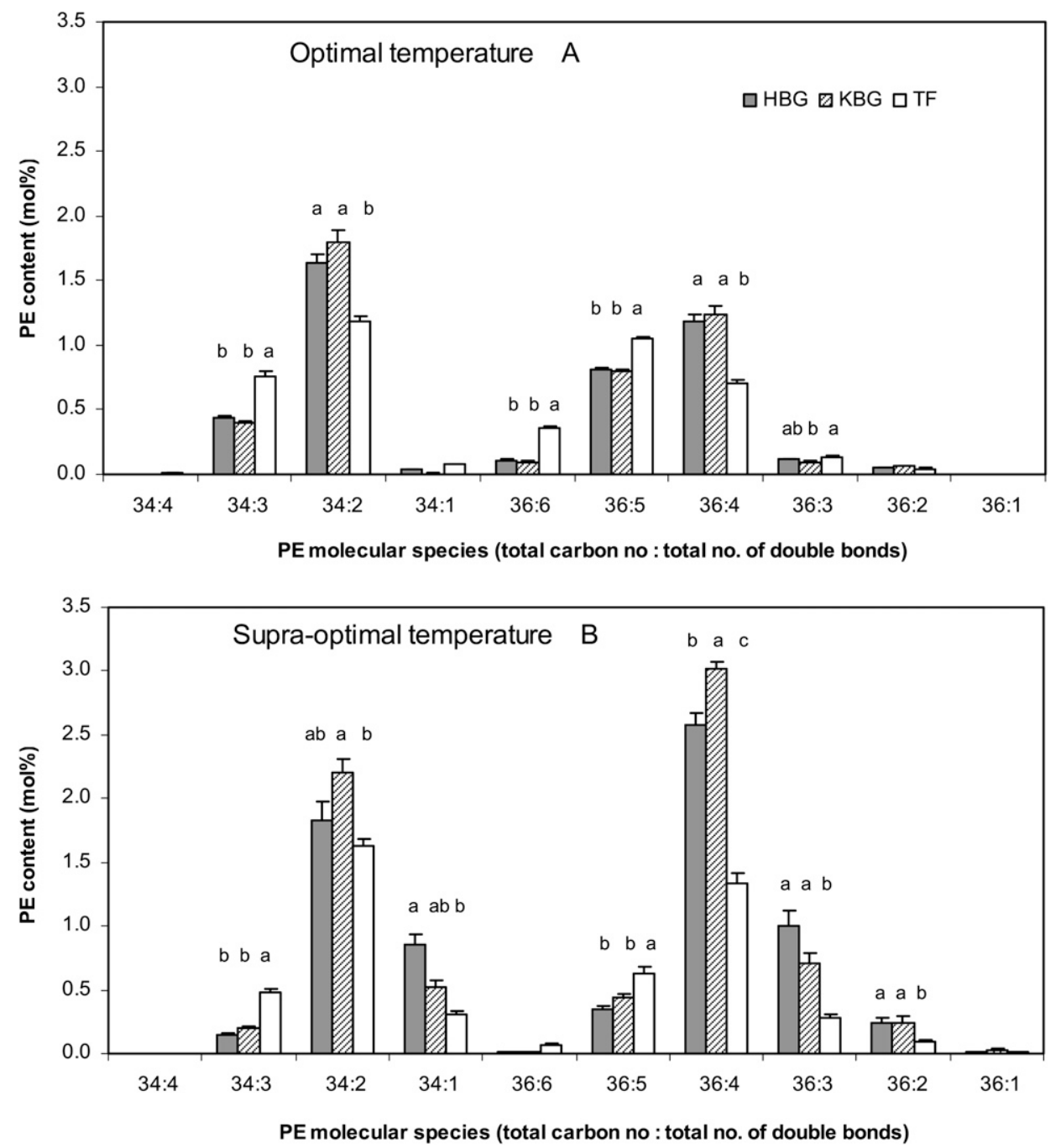

Fig. 4. The phosphatidylethanolamine (PE) molecular species composition (mol\%) of 'Thermal Blue' hybrid bluegrass (HBG), 'Apollo' kentucky bluegrass (KBG), and 'Dynasty' tall fescue (TF) under (A) optimal (22/ $15{ }^{\circ} \mathrm{C}, 14 / 10 \mathrm{~h}$ light/dark) and (B) supra-optimal $\left(35 / 25^{\circ} \mathrm{C}\right.$ and $40 / 30{ }^{\circ} \mathrm{C}, 14 / 10 \mathrm{~h}$ light/dark) temperatures. Means with the same letters in each PE molecular species were not significantly different (adjusting $P=0.05$ by the false discovery rate method). Error bars indicate $\pm \mathrm{SE}(\mathrm{n}=4$ or 5$)$. Means without letters indicated content 
(Table 1). Under optimal growth temperature, the three grasses had similar total phospholipid content, which ranged from $20.1 \%$ to $20.8 \%$ of total polar lipid content. At supra-optimal temperature, however, the total content of phospholipids increased in $\mathrm{HBG}$ and $\mathrm{KBG}$, but not in $\mathrm{TF}$; the total polar lipid content was $24.9 \%$ in $\mathrm{HBG}, 26.4 \%$ in $\mathrm{KBG}$, and $20.5 \%$ in $\mathrm{TF}$ after exposure to heat.

At supra-optimal temperature, the relative abundances of the phospholipid classes ranged from $10.4 \%$ to $12.2 \%$ for PC, $4.9 \%$ to $7.5 \%$ for $\mathrm{PE}$, and $2.7 \%$ to $4.3 \%$ for $\mathrm{PG}$, and was $\approx 1.8 \%$ for $\mathrm{PI}$ among the grasses (Table 1); PS, PA, and lysophospholipids were less prevalent and accounted for $0.5 \%$ to $0.7 \%, 0.2 \%$ to $0.3 \%$, and $0.03 \%$ to $0.05 \%$ of the total polar lipid content, respectively. The content of PC, PI, PS, and PA was similar among three grasses under supra-optimal growth temperature. The content of PE and PG, however, was higher in $\mathrm{HBG}$ and $\mathrm{KBG}$ than in TF under high temperature. The content of lysophospholipids (lysoPC + lysoPE + lysoPG) was highest in $\mathrm{KBG}$, lowest in $\mathrm{TF}$, and midway between KBG and TF in HBG. Our results are inconsistent with the notion that the membrane-destabilizing effect of lysophospholipids (Cullis and Dekruijff, 1979) plays a critical role in heat tolerance. The content of lysophospholipids, however, was very small; the total content of the three lysophospholipids (lysoPC, lysoPE, and lysoPG) was less than $0.05 \%$ of total polar lipid content.

PE, a major component of extraplastidic membranes (Moore, 1982), was the second most abundant class of phospholipid in the leaves of these turfgrasses (Table 1). Interestingly, PE content was similar among grasses under the optimal growth temperature, but PE was greater in the more heat-tolerant grasses (i.e., HBG and $\mathrm{KBG})$ than in TF after exposure to high temperature. This result is inconsistent with the general idea that PE functions as a membrane-destabilizing hexagonal phase-promoting phospholipid and that decreasing it would provide the most thermostability (Gruner, 1992; Seddon, 1990).

Profiling of $\mathrm{PE}$ revealed some molecular species that contained two polyunsaturated acyl species, such as 36:4 di 18:2, based on molecular composition of arabidopsis [Arabidopsis thaliana (L.) Heynh.] wild type (Columbia ecotype)\}, which increased and were higher in HBG and KBG than in TF after exposure to high temperature (Fig. 4; Welti et al., 2002). Our data also revealed that the DBI of PE was lower in HBG (3.32) and in KBG (3.27) than in TF (3.57) under optimal growth temperature (Table 2). After exposure to high $<0.1 \%$. heat, the DBI of PE decreased in all three grasses, and DBI of PE was lower in HBG (2.94) than in KBG (3.05) and TF (3.10). These results suggest that the saturation level of $\mathrm{PE}$ was greater in $\mathrm{HBG}$ than in $\mathrm{KBG}$ and $\mathrm{TF}$ under supra-optimal growth temperature. In addition, PC was an abundant phospholipid class in all three grasses (Table 1). Thus, our results are consistent with the notion that PE, particularly when it is more saturated, is compatible with membrane bilayer structure, when the PE is in combination with abundant PC (Tilcock et al., 1982; Silvius, 1986; Epand and Bottega, 1988; Seddon, 1990). However, it may also be that maintaining bilayer structure is a more pressing requirement for plastidic membranes (those containing bilayer-forming DGDG and nonbilayer-forming MGDG) than it is for extraplastidic membranes (those containing most of the bilayer-forming PC and nonbilayer-forming PE) during heat stress response.

PG is the major phospholipid in the thylakoid membranes of plant chloroplasts (Hagio et al., 2000; Welti et al., 2003). PG is
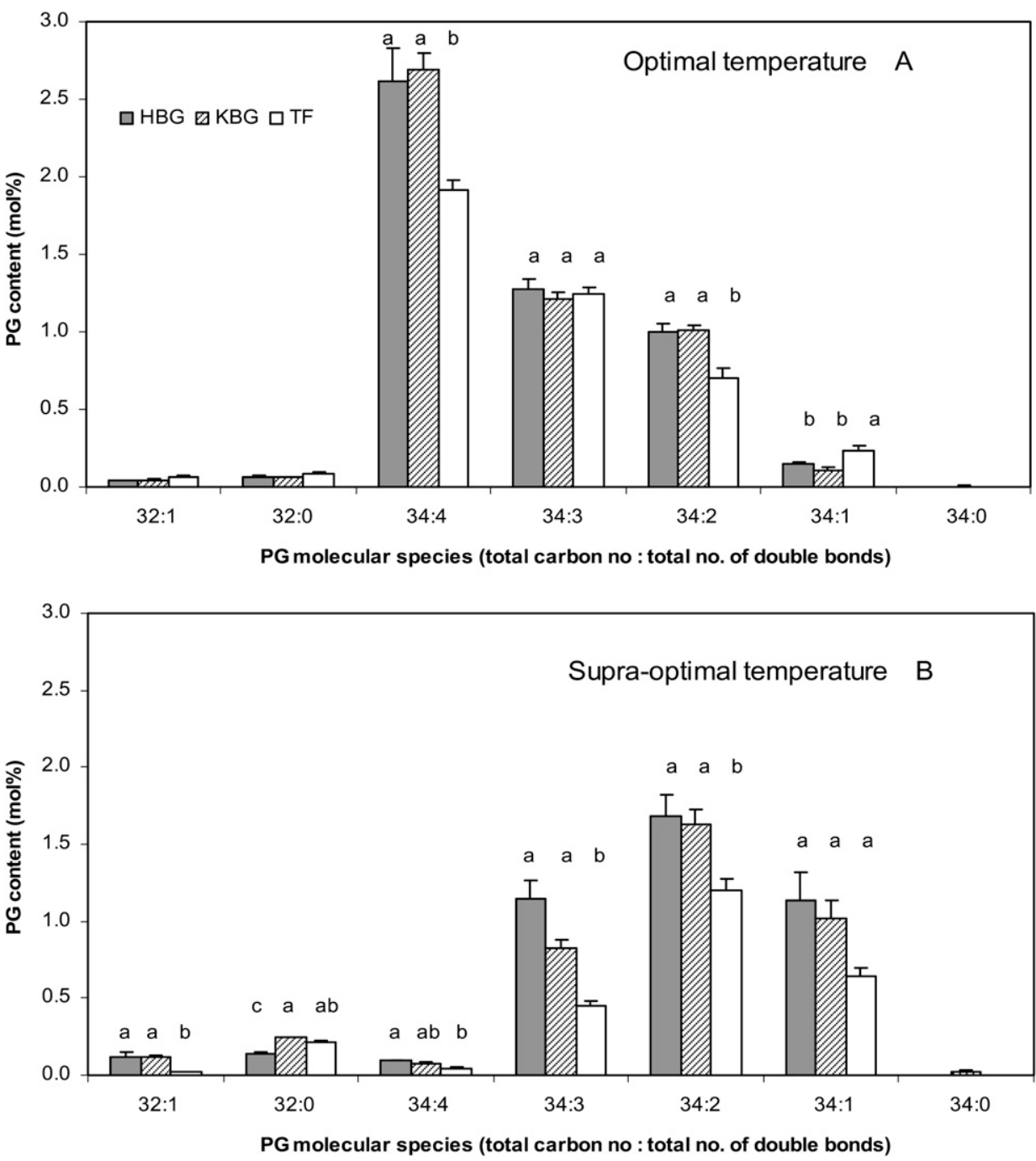

Fig. 5. The phosphatidylglycerol (PG) molecular species composition (mol\%) of 'Thermal Blue' hybrid bluegrass (HBG), 'Apollo' kentucky bluegrass (KBG), and 'Dynasty' tall fescue (TF) under (A) optimal (22/ $\left.15^{\circ} \mathrm{C}, 14 / 10 \mathrm{~h} \mathrm{light/dark}\right)$ and (B) supra-optimal $\left(35 / 25^{\circ} \mathrm{C}\right.$ and $40 / 30{ }^{\circ} \mathrm{C}, 14 / 10 \mathrm{~h}$ light/dark) temperatures. Means with the same letters in each PG molecular species were not significantly different (adjusting $P=0.05$ by the false discovery rate method). Error bars indicate $\pm \mathrm{SE}(\mathrm{n}=4$ or 5$)$. Means without letters indicated content 
considered to be essential for growth and development of the chloroplast. Hagio et al. (2000) and Sakurai et al. (2003), through their studies of a mutant that could not synthesize PG, determined that decreased PG content in thylakoid membranes inhibited photosynthesis. In our study, the content of PG was higher in HBG and KBG than in TF under optimal and supraoptimal temperature regimes (Table 1). The content of $\mathrm{PG}$ declined, however, in all three grasses after exposure to supraoptimal temperature; $\mathrm{PG}$ content declined by $16 \%$ in $\mathrm{HBG}$, $24 \%$ in $\mathrm{KBG}$, and $37 \%$ in TF. This decline of PG content among grasses after exposure to high temperature was likely caused by decreased 34:4-PG (18:3-16:1) and 34:3-PG (18:3-16:0 and 18:2-16:1) (Fig. 5; Welti et al., 2002). These results are consistent with the findings by others that exposure of plants to higher temperature led to reductions in linolenic acid (18:3) (Liu et al., 2006; Raison et al., 1982). It should be noted that the 16:1 fatty acid found in PG typically has a trans-3,4 double bond rather than the more common cis-double bonds of other fatty acid species (Ohnishi and Thompson, 1991), and the presence of this particular unsaturation may not relate to physical properties like the cis-double bonds. The presence of the trans 16:1 may explain the anomalous response of PG's DBI compared with the DBI of most other classes of lipids among the three grasses.

Potential MEMbrane LIPID MOLECUlaR BIOMARKERS FOR HEAT TOLERANCE. Although there were differences in membrane lipid content among grasses under optimal temperature, the differences became much greater after exposure to supraoptimal temperature for a number of lipids (e.g., MGDG, DGDG, PE, PG, and PS) (Table 1). Thus, different species of turfgrasses responded differently to heat stress in their compositional changes in membrane polar lipids.

Similar to heat tolerance, which was greatest in HBG and least in TF, the lipid profiles among the three grasses after exposure to high temperature indicated that the differences among three grasses were greatest between HBG and TF (Figs. 2-5; profiling of molecular species of other phospholipids not shown). Although HBG and KBG were more similar to each other than to TF, lipid content in KBG was numerically (albeit not statistically) midway between $\mathrm{HBG}$ and $\mathrm{TF}$ in a number of instances (e.g., MGDG, DGDG, and PG) (Table 1; Figs. 2-5). The composition of membrane lipid molecules under supraoptimal temperature may contribute to the differences in heat tolerances observed among these three grasses. Principal component analysis (PCA) simplified an otherwise complex process by reducing 152 lipid molecular species into 14 principal components (Davies, 2005). Two of the 14 PCs explained about $57.4 \%$ of the variance in the dataset (Fig. 6). The biggest differences were between TF and the bluegrasses (i.e., $\mathrm{HBG}$ and $\mathrm{KBG}$ ), which were separated primarily along the PC1 axis; PC1 explained $39.4 \%$ of the variance of the dataset. The HBG and KBG were separated primarily along the PC2 axis (PC2 explained $18.0 \%$ of the variance).

Inspection of the loadings of PC1 revealed 40 individual lipid molecular species that separated the more heat-tolerant bluegrasses (HBG and KBG) from less heat-tolerant TF (Table 3 ). According to lipid molecular species scores in PC1, 20 of the 40 significant lipid molecular species, which were greater in content in the grasses with greater heat tolerance (i.e., HBG and KBG), had high saturation levels (e.g., 34:1, 34:2, 36:1, 36:2, and 36:3). The remaining 20 lipid molecular species, which were lesser in content in the two grasses with greater heat

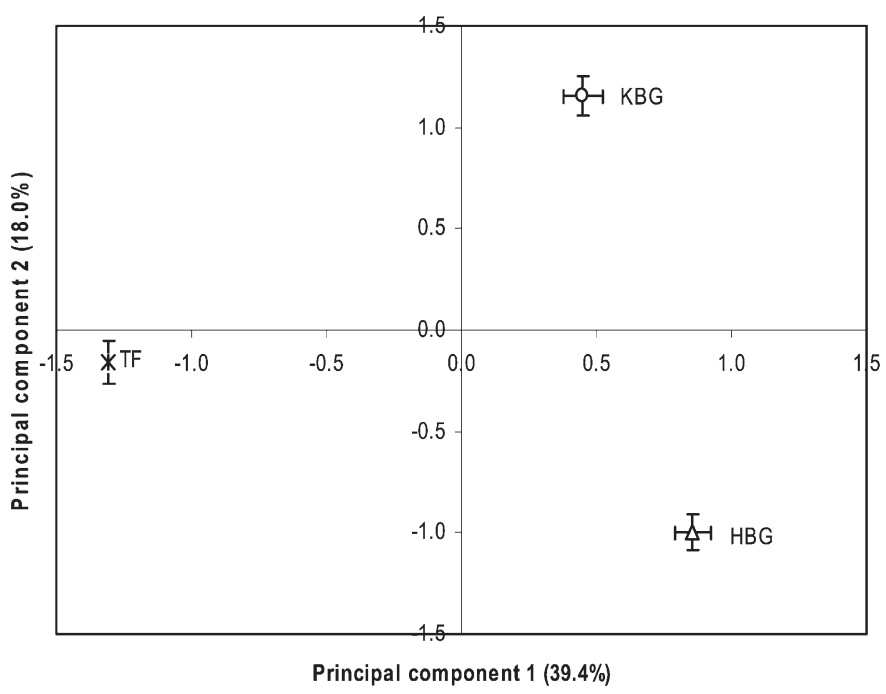

Fig. 6. Principal component analysis (PCA) of 152 lipid molecular species in 'Thermal Blue' hybrid bluegrass (HBG), 'Apollo' kentucky bluegrass (KBG), and 'Dynasty' tall fescue (TF); Principal component (PC) 1 and PC2 accounted for $39.4 \%$ and $18.0 \%$, respectively, of the variance of the dataset, for a total of approximately $57.4 \%$.

Table 3. Forty membrane lipid molecular species that were significantly different in the bluegrasses ['Thermal Blue' hybrid bluegrass (HBG) and 'Apollo' kentucky bluegrass (KBG)] compared with 'Dynasty' tall fescue (TF) after exposure of grasses to supra-optimal $\left(35 / 25^{\circ} \mathrm{C}\right.$ and $40 / 30{ }^{\circ} \mathrm{C}, 14 \mathrm{~h}$ light $/ 10 \mathrm{~h}$ dark) temperatures. These lipid molecular species may be potential biomarkers for heat tolerance in cool-season turfgrasses.

\begin{tabular}{lllll}
\hline \multicolumn{4}{c}{ Present in greater amounts in more heat-tolerant turfgrasses ${ }^{z}$} \\
\hline PS 36:1 & PS 34:1 & PC 34:1 & MGDG 36:4 & PS 36:4 \\
PG 34:2 & PC 36:2 & PS 36:3 & PE 36:4 & MGDG 36:2 \\
DGDG 36:1 & MGDG 36:3 & PE 36:2 & PE 34:1 & PC 36:3 \\
PC 36:1 & DGDG 36:3 & DGDG 36:4 & PE 36:3 & DGDG 36:2
\end{tabular}

Present in lesser amounts in more heat-tolerant turfgrasses ${ }^{2}$

\begin{tabular}{lllll}
\hline MGDG 34:3 & MGDG 36:5 & DGDG 34:3 & DGDG 36:5 & MGDG 36:6 \\
DGDG 36:6 & PC 34:3 & PC 36:6 & PI 34:3 & PE 34:3 \\
PC 36:5 & PI 36:5 & PS 42:3 & PE 36:6 & PS 34:3 \\
PC 34:4 & PE 34:4 & PS 40:3 & PE 36:5 & PC 38:6
\end{tabular}

${ }^{\mathrm{z}}$ More heat-tolerant turfgrasses refer to HBG and KBG in this study; $\mathrm{PS}=$ phosphatidylserine, $\mathrm{PC}=$ phosphatidylcholine, $\mathrm{MGDG}=$ monogalactosyldiacylglycerol, $\mathrm{PG}=$ phosphatidylglycerol, $\mathrm{PE}=$ phosphatidylethanolamine, DGDG = digalactosyldiacylglycerol, PI = phosphatidylinositol.

tolerance (i.e., HBG and $\mathrm{KBG}$ ), have high unsaturation levels [i.e., 36:6 (di 18:3) and 36:5 (18:3-18:2)]. These results were consistent with the finding that there was correlation between the low content of 18:3 and tolerance to high-temperature stress in tomato (Solanum lycopersicum L.) (Liu et al., 2006).

In general, $\mathrm{HBG}$ and $\mathrm{KBG}$ have more saturated lipid species and exhibit greater heat tolerance than TF. These results suggest 40 membrane lipid species as potential biomarkers for heat tolerance in cool-season turfgrasses (Table 3). Further experiments are needed to validate candidate lipid biomarkers by analyzing additional heat-tolerant cool-season turfgrasses. 


\section{Conclusions}

Our data indicate that supra-optimal growth temperature caused compositional changes of membrane polar lipids among three grasses, including a heat-tolerant HBG ('Thermal Blue'), a medium heat-tolerant KBG ('Apollo'), and a heat-sensitive TF ('Dynasty'). Heat-tolerant $\mathrm{HBG}$ and $\mathrm{KBG}$ had higher contents of DGDG, greater ratios of DGDG-to-MGDG, and greater saturation of fatty acids than a more heat-sensitive TF under supra-optimal growth temperature. There were also greater contents of $\mathrm{PE}$ and $\mathrm{PG}$ in $\mathrm{HBG}$ and $\mathrm{KBG}$ than in $\mathrm{TF}$ under high temperature. Results suggest 40 membrane lipid molecular species as potential biomarkers for heat tolerance in cool-season turfgrasses.

\section{Literature Cited}

Armond, P.A., O. Bjorkman, and L.A. Staehelin. 1980. Dissociation of supramolecular complexes in chloroplast membranes. A manifestation of heat damage to thephotosynthetic apparatus. Biochim. Biophys. Acta 601:433-442.

Bremer, D.J. 2003. Evaluation of microlysimeters used in turfgrass evapotranspiraton studies using the dual-probe heat-pulse technique. Agron. J. 95:1625-1632.

Brügger, B., G. Erben, R. Sandhoff, F.T. Wieland, and W.D. Lehmann. 1997. Quantitative analysis of biological membrane lipids at the low picomole level by nano-electrospray ionization tandem mass spectrometry. Proc. Natl. Acad. Sci. USA 94:2339-2344.

Chen, J., J.J. Burke, Z. Xin, C. Xu, and J. Velten. 2006. Characterization of the Arabidopsis thermosensitive mutant atts02 reveals an important role for galactolipids in thermotolerance. Plant Cell Environ. 29:1437-1448.

Cullis, P.R. and B. Dekruijff. 1979. Lipid polymorphism and the functional roles of lipids in biological membranes. Biochim. Biophys. Acta 559:399-420.

Davies, A.M.C. 2005. Back to basics: Applications of principal component analysis. Spectroscopy Europe 17:30-31.

Devaiah, S.P., M.R. Roth, E. Baughman, M. Li, P. Tamura, R. Jeannotte, R. Welti, and X. Wang. 2006. Quantitative profiling of polar glycerolipid species and the role of phospholipase D $\alpha 1$ in defining the lipid species in Arabidopsis tissues. Phytochemistry 67:1907-1924.

Di Baccio, D., M.F. Quartacci, F.D. Vecchia, N. La Rocca, N. Rascio, and F. Navari-Izzo. 2002. Bleaching herbicide effects on plastids of dark-grown plants: Lipid composition of etioplasts in amitrole and norflurazon-treated barley leaves. J. Expt. Bot. 53: 1857-1865.

Dunn, J.H. and K. Diesburg. 2004. Turf management in the transition zone. Wiley, Hoboken, NJ.

Epand, R.M. and R. Bottega. 1988. Determination of the phase behaviour of phosphatidylethanolamine admixed with other lipids and the effects of calcium chloride: Implications for protein kinase $\mathrm{C}$ regulation. Biochim. Biophys. Acta 944:144-154.

Grover, A., M. Agarwal, S. Katiyar-Argarwal, C. Sahi, and S. Argarwal. 2000. Production of high temperature tolerant transgenic plants through manipulation of membrane lipids. Curr. Sci. 79:557559.

Gruner, S.M. 1992. Nonlamellar lipid phases, p. 211-250. In: P.L. Yeagle (ed.). The structure of biological membranes. CRC Press, Boca Raton, FL.

Hagio, M., Z. Gombos, Z. Va'rkonyi, K. Masamoto, N. Sato, M. Tsuzuki, and H. Wada. 2000. Direct evidence for requirement of phosphatidylglycerol in photosystem II of photosynthesis. Plant Physiol. 124:795-804.

Han, X. and R.W. Gross. 2005. Shotgun lipidomics: Electrospray ionization mass spectrometric analysis and quantitation of cellular lipidomes directly from crude extracts of biological samples. Mass Spectrom. Rev. 24:367-412.

Haucke, V. and G. Di Paolo. 2007. Lipids and lipid modifications in the regulation of membrane traffic. Curr. Opin. Cell Biol. 19:426435.

Kleinschmidt, M.G. and V.A. McMahon. 1970. Effect of growth temperature on the lipid composition of Cyanidium caldarium. Plant Physiol. 46:290-293.

Lea, P.J. and R.C. Leegood. 1993. Plant biochemistry and molecular biology. Wiley, Chichester, UK.

Liu, X., J. Yang, B. Li, X. Yang, and Q. Meng. 2006. Antisensemediated depletion of tomato chloroplast omega-3 fatty acid desaturase enhances thermal tolerance. J. Integr. Plant Biol. 48:10961107.

Marcum, K.B. 1998. Cell membrane thermostability and wholeplant heat tolerance of kentucky bluegrass. Crop Sci. 38:12141218.

Moore, T.S. 1982. Phospholipid biosynthesis. Annu. Rev. Plant Physiol. 33:235-259.

National Assessment Synthesis Team. 2000. Climate change impacts on the United States: The potential consequences of climatic variability and change. U.S. Global Change Research Program, Washington, DC.

Ohnishi, M. and G.A. Thompson, Jr. 1991. Biosynthesis of the unique trans-delta 3- hexadecenoic acid component of chloroplast phosphatidylglycerol: Evidence concerning its site and mechanism of formation. Arch. Biochem. Biophys. 288:591-599.

Pearcy, R.D. 1978. Effect of growth temperature on the fatty acid composition of the leaf lipids in Atriplex lentiformis (Torr.) Wats. Plant Physiol. 61:484-486.

Quinn, P.J. 1988. Effects of temperature on cell membranes. Symp. Soc. Exp. Biol. 42:237-258.

Raison, J.K., J.K.M. Roberts, and J.A. Berry. 1982. Correlations between the thermal stability of chloroplast (thylakoid) membranes and the composition and fluidity of their polar lipids upon acclimation of the higher plant, Nerium oleander, to growth temperature. Biochim. Biophys. Acta 688:218-228.

Read, J.C., J.A. Reinert, P.F. Colbaugh, and W.E. Knoop. 1999. Registration of 'Reveille' hybrid bluegrass. Crop Sci. 39: 590.

Sakurai, I., M. Hagio, Z. Gombos, T. Tyystjärvi, V. Paakkarinen, E. Aro, and H. Wada. 2003. Requirement of phosphatidylglycerol for maintenance of photosynthetic machinery. Plant Physiol. 133:13761384.

Seddon, J.M. 1990. Structure of the inverted hexagonal $\left(\mathrm{H}_{\mathrm{II}}\right)$ phase, and non-lamellar phase transitions of lipids. Biochim. Biophys. Acta 1031:1-69.

Shoemaker, D.P., C.W. Garland, and D.P. Steinfeld. 1974. Experiments in physical chemistry. McGraw-Hill, New York.

Silvius, J.R. 1986. Solid- and liquid-phase equilibria in phosphatidylcholine/phosphatidylethanolamine mixtures. A calorimetric study. Biochim. Biophys. Acta 857:217-228.

Stupnikova, I., A. Benamar, D. Tolleter, J. Grelet, G. Borovskii, A. Dorne, and D. Macherel. 2006. Pea seed mitochondria are endowed with a remarkable tolerance to extreme physiological temperature. Plant Physiol. 140:326-335.

$\mathrm{Su}$, K., D.J. Bremer, S.J. Keeley, and J.D. Fry. 2007. Effects of high temperature and drought on a hybrid bluegrass compared with kentucky bluegrass and tall fescue. Crop Sci. 47:2152-2161.

Suss, K.-H. and I. Yordanov. 1986. Biosynthetic cause of vivo acquired thermotolerance of photosynthetic light reactions and metabolic responses of chloroplasts to heat stress. Plant Physiol. 81:192-199.

Tilcock, C.P., M.B. Bally, S.B. Farren, and P.R. Cullis. 1982. Influence of cholesterol on the structural preferences of dioleoylphosphatidylethanolamine-dioleoylphosphatidylcholine systems: A phosphorus31 and deuterium nuclear magnetic resonance study. Biochemistry 21:4596-4601. 
Vigh, L., D.A. Los, I. Horvath, and N. Murata. 1993. The primary signal in the biological perception of temperature: Pd-catalyzed hydrogenation of membrane lipids stimulated the expression of the desA gene in Synechocystis PCC6803. Proc. Natl. Acad. Sci. USA 90:9090-9094.

Wang, S.Y. and H.S. Lin. 2006. Effects of plant growth temperature on membrane lipids in strawberry (Fragaria $\times$ ananassa Duch.). Scientia Hort. 108:35-42.

Wang, X. 2004. Lipid signaling. Curr. Opin. Plant Biol. 7:329-336.

Webb, M.S. and B.R. Green. 1991. Biochemical and biophysical properties of thylakoid acyl lipids. Biochim. Biophys. Acta 1060:133-158.

Weis, E. and J.A. Berry. 1988. Plants and high temperature stress. Symp. Soc. Exp. Biol. 42:329-346.
Welti, R., W. Li, M. Li, Y. Sang, H. Biesida, H. Zhou, C.B. Rajashekar, T.D. Williams, and X. Wang. 2002. Profiling membrane lipids in plant stress responses. J. Biol. Chem. 277:31994-32002.

Welti, R. and X. Wang. 2004. Lipid species profiling: A high throughput approach to identify lipid compositional changes and determine the function of genes involved in lipid metabolism and signaling. Curr. Opin. Plant Biol. 7:337-344.

Welti, R., J. Shah, W. Li, M. Li, J. Chen, J.J. Burke, M. Fauconnier, K. Chapman, M. Chye, and X. Wang. 2007. Plant lipidomics: Discerning biological function by profiling plant complex lipids using mass spectrometry. Front. Biosci. 12:2494-2506.

Welti, R., X. Wang, and T.D. Williams. 2003. Electrospray ionization tandem mass spectrometry scan modes for plant chloroplast lipids. Anal. Biochem. 314:149-152. 